\section{RESEÑ A S}

Jürgen Untermann; Michael Koch, Javier de Hoz, Joaquín Gorrochategui (eds.), Monumenta Linguarum Hispanicarum. Band VI. Die vorrömische einheimische Toponymie des antiken Hispanien, Wiesbaden: Dr. Ludwig Reichert, 2018. ISBN 978-3-95490-197-5.

Se publica de forma póstuma el sexto tomo de la magna obra del investigador alemán Jürgen Untermann Monumenta Linguarum Hispanicarum, compuesta por varios volúmenes dedicados al estudio de la epigrafía prerromana en la península ibérica. El autor, quien ya poseía una amplia bibliografía sobre los estudios de las lenguas y escrituras paleohispánicas, cierra con este trabajo, lleno de erudición, la temática de compendio de materiales lingüísticos en torno a la península ibérica en la antigüedad dedicando el presente volumen a la toponimia.

No obstante, la obra no concluye con este sexto tomo, dado que se completa con un séptimo dedicado al léxico ibérico, de reciente publicación (2019), complementando el V de la serie que ya realizara Dagmar Wodtko en el año 2000 acerca del léxico celtibérico (V.1. Wörterbuch der keltiberischen Inschriften). Este tomo V.2 fue propuesto por el mismo Untermann y ha sido realizado por Javier Velaza y Noemí Moncunill (V.2. Lexicon der iberischen Inschriften).

La obra que referimos en esta reseña ha visto la luz gracias al trabajo conjunto del profesor $\mathrm{Mi}$ chael Koch, historiador especialista en historia antigua de la península ibérica, y a los profesores expertos en lingüística y epigrafía paleohispánicas Javier de $\mathrm{Hoz}$ (Universidad Complutense de Madrid) ${ }^{1}$ y Joaquín Gorrochategui (Universidad

1 Desde aquí también mi recuerdo a Javier de Hoz, quien nos dejó, ya publicada la obra, el 12 de enero de 2019. Que las almas de ambos investigadores descansen en paz dondequiera que estén, en grata compañía mutua. del País Vasco/Euskal Herriko Unibertsitatea), colegas por muchos años del autor. Michael Koch llamó a colaborar a Javier de Hoz y a Joaquín Gorrochategui tras haber recibido directamente de su autor el manuscrito de la obra, así como la tarea de culminar su edición y consecuente publicación.

En primer lugar, la obra comienza con un prólogo a cargo de Michael Koch, quien expone cómo se ha ido desarrollando el proceso de creación y edición de la obra hasta su publicación, desde las manos de su autor hasta pasar a las de sus editores. A continuación, se inicia la obra en sí misma, con el habitual índice y su introducción, que se abre con la bibliografía y listado de abreviaturas. Seguidamente en el texto de la introducción el autor realiza un breve repaso sobre la situación lingüística de la península ibérica en la antigüedad, pasando por las distintas zonas lingüísticas existentes en ella, es decir, la zona indoeuropea y la no indoeuropea, ya definidas por Gómez-Moreno $(1925,1949)$. Todo ello constituye un completo estado de la cuestión sobre el tema, al que incorpora su propia opinión, para lo cual abarca tanto lo lingüístico, lo histórico, lo geográfico y lo arqueológico. La minuciosidad del autor en toda la introducción es sorprendente. En ella explica cada punto con el máximo detalle, tanto el estado de la cuestión como la estructura de su obra, así como los motivos que le llevan a tomar ciertas decisiones, como la inclusión o exclusión de un topónimo.

Tras la introducción se añaden unas observaciones generales sobre la obra. Aquí el autor comenta tanto la estructura del libro como ciertas disquisiciones sobre el corpus de datos que ha compendiando y utilizado. Los editores, además, añaden algunas indicaciones acerca de los lemmata mediante las cuales explican por qué razones algunas fuentes no aparecen citadas en la obra, como son el papiro de Artemidoro, el itinerario de barro y la Ora Maritima de Avieno, principalmente.

A pesar de la omisión de algunas fuentes la bibliografía, de la obra es muy amplia, lo que de- 
muestra el gran manejo de las fuentes antiguas y modernas del autor. Asimismo, los editores han completado esta bibliografía continuando el método del propio Untermann, a saber, la revisión de los tomos de la revista Hispania Epigraphica (Madrid) en la que se publican las novedades epigráficas de la Hispania antigua. Untermann llegó a revisar los siete primeros tomos, y los editores se han ocupado de continuar hasta el décimo octavo.

La estructura de los lemas está perfecta y claramente organizada. Cada uno está dividido en letras $(\mathrm{A}, \mathrm{B}, \mathrm{C})$ que organizan la información. En primer lugar (A), se presentan las fuentes, clasificadas a su vez por tipos, desde las más directas a las indirectas: primero las epigráficas, es decir, monedas e inscripciones en lengua prerromana, y a continuación en latín o en griego; seguidamente se ofrece una relación de las fuentes antiguas de autores latinos y griegos donde se cita el topónimo, ya sean itinerarios, obras narrativas o poéticas. En segundo lugar (B), expone la situación geográfica actual del topónimo. Y por último $(\mathrm{C})$, trata el desarrollo lingüístico del topónimo y lo adscribe a la lengua de la que procede. En cada sección se incluyen referencias bibliográficas y comentario a algunas de ellas.

La información de cada topónimo se presenta de forma concisa y clara, pero no por ello es escasa o adolece de falta información, sino al contrario. La labor realizada por los editores es asimismo magnífica, respetando el trabajo inicial del autor $y$, como ya se ha comentado, agregando, mediante unos notorios corchetes, sus propias adiciones, que completan la obra.

Lingüísticamente Untermann divide la península ibérica en las dos partes bien diferenciadas a través de la frontera que se establece, por una parte, por los topónimos de raíz indoeuropea celta brig-, término celta para 'oppidum', y los topónimos formados con la palabra ili-, ilu-, 'ciudad' (también en NNP); y, por otra parte, por un muy uniforme repertorio de topónimos y antropónimos.

En relación a la clasificación lingüística de la zona indoeuropea de la península ibérica la teoría del autor se opone a la communis opinio iniciada desde Tovar (1966/67) y discusión aún hoy en día abierta. Esta defiende que entre las lenguas indo- europeas de la península ibérica no todas provienen de un origen celta, sobre todo a través del testimonio del lusitano que mantiene la $p$-inicial. Sin embargo, Untermann sostiene la existencia de un «hispano-celta», esto es, que todas las lenguas de la familia lingüística indoeuropea en la península ibérica pertenecen a la subfamilia de las lenguas celtas. No obstante, acepta el hecho de que en una zona tan grande (desde el Ebro hasta Galicia, desde la costa cantábrica hasta el Algarve) no se guarde una uniformidad homogénea y que por tanto el tronco indoeuropeo peninsular ha de descomponerse en dialectos independientes, pero próximos entre sí. Por ello divide a su vez estas lenguas hispano-célticas en dos grandes bloques: dialectos del este (entre los que se incluye el celtibérico) con pérdida de la consonante $p$ originaria a comienzo de palabra e intervocálica; y dialectos noroccidentales y orientales (mejor representado por el lusitano), en los que este cambio aún no ha sucedido en época antigua. Asimismo, para la distinción de estas lenguas hispano-celtas señala las características atestiguadas más frecuentes como son los NNL en -brig/-briga, bri-, compuestos con-dunum, -magus y-durum, derivados mediante el sufijo -aiko, y la palabra ocelum.

Respecto a la zona no indoeuropea, que como bien señala el autor ocupa un territorio que va desde el este de Andalucía hasta los Pirineos, y por el Mediterráneo hasta el oppidum de Ensérune en Béziers, destaca la gran uniformidad de testimonios epigráficos y onomásticos. Entre las lenguas existentes en esta zona, Untermann distingue el ibérico, el vascón (en el $\mathrm{N}$ de Huesca y Navarra) y el tartésico. En cuanto a la idea de que el ibérico hubiera sido una lengua vehicular, como defendía J. de Hoz, Untermann no se posiciona al respecto.

Asimismo, expone algunos de los rasgos que caracterizan a estas lenguas y que le llevan a clasificar un topónimo en una u otra lengua, aunque en algunos casos el autor no está seguro de su segura adscripción. Por ello lo señala con dudas ofreciendo varias posibilidades de la siguiente forma: «tartessisch oder iberisch" ('tartésico o ibérico') o «iberisch oder vaskonisch» ('ibérico o vascón'). Los rasgos lingüísticos que distingue Untermann para definir un topónimo como ibérico son: -ili-, -ilu-, -ilti-, -iltu-, que también está presente en antropónimos, y el sufijo -sken, presente en las monedas 
y equivalente a las fuentes griegas y latinas -itani, -etani y -etes. Mientras que para la clasificación de un topónimo como tartésico señala los morfos ipI-ippo y ob-/-obal-uba, -igi, -tigi (como segundo elemento de composición).

En cuanto a la denominación de la lengua de las estelas del suroeste como tartésico, Untermann sigue moviéndose por el mismo criterio que en el tomo de la misma obra dedicada a estas inscripciones (tomo IV). Es lógico que el autor prefiera mantener una coherencia dentro de su propia obra, aun siendo este volumen muy posterior al precedente. Su criterio para elegir esta denominación se basaba en su adecuación etnográfica, en contra del término "turdetano», que, aunque equivalente - pues designa una realidad geográfica similar-, es un término etnográfico antiguo que posiblemente ya no se usaba en tiempos de las inscripciones del SO (MLH IV, 96). En contra de este término para referirse a esta lengua, véase De Hoz, quien no creía que esta lengua perteneciera al pueblo de Tartessos.

Los posibles antecedentes a la obra de Untermann que pueden citarse son dos: la obra Iberische Landeskunde de Antonio Tovar publicada en tres tomos $(1974,1976,1989)$ y la Tabula Imperii Romani (TIR. Oxford University Press: 1934, 1939, 1987). La primera de las obras, la de Tovar, dividía la información entre las tres provincias en las que Augusto dividió Hispania: Baetica, Lusitania y Tarraconensis. Pero Tovar centraba su obra en los aspectos históricos y culturales (el mismo título de la obra lo deja bien claro: «Cultura y civilización ibérica») más que en los lingüísticos, lo que hace a ambas obras diferentes, desde la perspectiva a partir de la cual se abordan cada una de ellas. Los datos ofrecidos por Tovar en extenso, Untermann los suple aportando la bibliografía como referencia a consultar. Sin embargo, son obras parejas y complementarias. Además, la nueva obra de Untermann actualiza la información publicada por Tovar, gracias a los avances en la investigación arqueológica, histórica y lingüística. Sirva para ilustrar este punto el topónimo de la ciudad celtibérica de Segeda (Tovar 1989, 413; MLH VI, 632) cuya localización geográfica exacta aún es desconocida para Tovar. Tras las excavaciones realizadas durante años por Francisco Burillo y su equipo en la población zaragozana de Mara se confirmó la si- tuación geográfica de este topónimo, como bien actualiza Untermann, en la localidad de Belmonte (de Gracián), a unos $10 \mathrm{~km}$ de Calatayud, contigua a Mara.

Por otro lado, en comparación con la Tabula Imperii Romani, al igual que ocurría con la obra de Tovar, ambos trabajos abordan la toponimia antigua de la península ibérica desde aspectos diferentes. En el caso de la Tabula se concentra en el aspecto geográfico, pues su objetivo es realizar una completa topografía cartográfica de la antigüedad romana. Por ello no entra en detalles sobre el nombre del topónimo y básicamente se ocupa en localizarlo geográficamente.

Han de añadirse dos antecedentes más, aunque parciales: la publicación de García Alonso de 2003 acerca de la toponimia de Ptolomeo, y la obra de Correa de 2016 para la Bética. La primera de estas obras sigue muy de cerca la obra de Tovar arriba citada, a la que añade datos etimológicos, de los que suele carecer la obra de Tovar. La obra de Correa, aun sin abarcar toda la península, es la más completa y la que más se asemeja al trabajo de Untermann. Cada entrada contiene datos sobre las fuentes, etimología, sobrenombres (si los tiene), situación geográfica, con una prolija pero concisa explicación, como hace el autor alemán. Untermann, por el contrario, resume aún más la información, sin obviar ningún dato fundamental para la explicación de cada topónimo, como ya se ha señalado más arriba.

Si comparamos alguna de las entradas con todos estos antecedentes veremos que la publicación de Tovar sienta, en parte, las bases para la ordenación del material toponímico de la península, que se ha ido completando paulatinamente en las sucesivas obras, y perfeccionándose en la obra de Untermann. He tomado tres ejemplos que pueden ilustrarnos esta trayectoria de los estudios sobre toponimia de la Hispania antigua. El topónimo es una buena muestra, dada la complejidad que exhibe en varios aspectos, en cuanto a su nomenclatura y situación geográfica. La base principal para el conocimiento de este topónimo son las monedas con leyenda indígena y con leyenda latina, pero también las diversos epígrafes latinos y las fuentes clásicas (Plinio, Ptolomeo, Esteban de Bizancio) donde no solo se atestigua el topónimo como Ili- 
berris ( I $I \lambda_{1} \beta \varepsilon \rho i ́ c$, ILIBERI, Iliberri) sino también con el sobrenombre FLORENTIA y el nombre indígena iltuŕir. Tovar y García Alonso ofrecen esta información, y Correa además ordena y presenta todos los testimonios existentes. Untermann, a su vez, presenta la misma información, la ordena y selecciona los datos más relevantes, y la expone de forma muy clara e intuitiva. Untermann explica con claridad por qué monedas con leyenda aparentemente tan diferente proceden de la misma ceca («Dass die iber. und lat. Legenden der gleichen Münzstätte entstammen, wird durch die Münzbilder sichergestellt») y expone los problemas de lectura de la leyenda con letrero indígena (signario utilizado y lectura del tercer signo). En cuanto a las fuentes bibliográficas, Tovar presentaba como referencias a Plinio, a Ptolomeo y a Esteban de Bizancio, con dudas. Correa y Untermann, sin embargo, no lo citan. Referente a la localización geográfica, otro de los problemas concernientes al topónimo de Iliberris, supuso una importante discusión científica en la Granada de finales del siglo XIx, y que finalmente dirimió Gómez-Moreno a principios del siglo xx (1905). La comunidad científica se dividía en los que defendían la situación del topónimo en Medina Elvira, los llamados elviristas, y los que defendían su situación en la Alcazaba de Granada, los alcazabistas. Las fuentes epigráficas y los testimonios de época árabe inclinaron la balanza hacia la zona de la alcazaba de Granada. Tovar, junto a él García Alonso, resume esta problemática. Correa la omite y Untermann ofrece su emplazamiento actual, sin entrar en detalles, pero que sin embargo no obvia, pues los expone a través de la bibliografía, explicando brevemente algunos de los puntos conflictivos. Y por último, en relación a la etimología, Correa presenta el desarrollo diacrónico del topónimo y García Alonso es el primero que añade una explicación, ili- 'ciudad' y $b e-$ rri 'nuevo', y que Untermann mantiene. Ambos términos indígenas, el primero, palabra ibérica y el segundo que el investigador alemán relaciona con el testimonio aquitano lurberixo (dat. sg.) y ambos autores a su vez con el término vasco 'nuevo'. García Alonso se pregunta si el topónimo puede interpretarse como 'Villanueva', referido a un asentamiento de reciente creación. En resumen, la obra de Untermann expone este topónimo de manera magistral. Resuelve su problemática asociada con concisión y precisión, mostrando los datos más significativos y completando con las referencias bibliográficas los datos que han servido de base para dirimir este topónimo.

Un segundo ejemplo es el topónimo Artigi, de clara adscripción indígena por su terminación en -(t)igi, de difícil explicación, dado que las fuentes ofrecen datos contradictorios sobre él. Tovar llega a la conclusión de que se trata de dos topónimos diferentes, uno situado al norte, en Zalamea de la Serena (Badajoz), Iulipa, y otro al sur del Guadalquivir. Así lo repiten los autores posteriores, pero en la presente obra el autor alemán ha sabido resolver de forma notable y pragmática esta problemática. Divide la entrada de este topónimo en dos entradas. De este modo consigue presentar los datos que hacen referencia a cada uno de estas dos formas homónimas y entender qué fuentes hacen referencia a cada una de ellas, su localización y su etimología, que comparten. En consecuencia, la Artigi situada hoy día en Zalamea de la Serena se cita en el Itinerario Antonino y la Artigi localizada en una zona aún inexacta entre Andalucía y el río Guadalquivir está documentada en Plinio $(3,10)$ y Ptolomeo $(2,4,11)$. En cuanto a su etimología, aunque es claramente indígena, Untermann prefiere mantener una postura prudente, con respecto a los autores anteriores que la daban como tartesia, y la clasifica como «ein iber. oder tartess. ON» («un nombre de lugar ibérico o tartésico»).

Por otra parte, el propio Untermann había tratado la materia directamente o indirectamente en diferentes trabajos en modo de artículos como Elementos de un atlas antroponímico de la Hispania Antigua (1965), "Le nom de Narbonne et la langue de ses habitants» (Col. Narbonne, 1973, 163167), «Los etnónimos de la Hispania antigua y las lenguas prerromanas de la Península Ibérica» (Enc. Bouza Brey, 1992, 367-397), "La toponimia antigua como fuente de las lenguas hispano-celtas» (Palaeohispanica 1, 2001).

Era necesaria una obra que tratara la toponimia de la península ibérica desde el punto de vista más lingüístico y no tanto histórico o geográfico como ya habían hecho las anteriores obras de referencia, como son el Iberische Landeskunde de A. Tovar $(1976,1978,1987)$, con un enfoque histórico y cultural, y la Tabula Imperii Romani (TIR), con 
un enfoque geográfico. La obra del autor alemán, aun siendo más lingüística, es mucho más completa que sus precedentes, dado que ofrece todos los datos esenciales para la comprensión del topónimo, ya sean geográficos, historiográficos o lingüísticos. Y además no solo incluye los topónimos en su forma de sustantivo sino también adjetival, tanto gentilicios como adjetivos derivados del topónimo original (los que señala mediante un asterisco).

Además, como se ha ido comentado, toda la obra está aderezada de una escrupulosidad, detallismo, pulcritud y erudición máximas que la convierten en una obra de consulta fundamental e imprescindible para los estudios de la península ibérica en la antigüedad, y que viene a cubrir un vacío en las publicaciones acerca de la Hispania antigua.

\section{BiBLIOGRAFÍA}

Correa, J. A., 2016, Toponimia antigua de Andalucía, Sevilla: Universidad de Sevilla.

García Alonso, J. L., 2003, La Península Ibérica en la Geografía de Claudio Ptolomeo, Anejos de Veleia, Vitoria-Gasteiz: Universidad del País Vasco.

Gómez-Moreno, M., 1905, «De Iliberri a Granada», Boletín de la Academia de la Historia, 44-61.

Gómez-Moreno, M., 1925, "Sobre los íberos y su lengua», en: Homenaje a Menéndez-Pidal, III, 475-499.

Gómez-Moreno, M., 1949, Misceláneas: historia, arte y arqueología, Madrid: Consejo Superior de Investigaciones Científicas.

De Hoz, J., 2010, Historia Lingüistica de la Península Ibérica. I. Preliminares y mundo meridional prerromano, Madrid: Consejo Superior de Investigaciones Científicas.
Tovar, A., 1966/1967, "L'inscription du Cabeço das Fraguas et la langue des Lusitaniens", Études Celtiques 11, 237-268.

Tovar, A., 1974, Iberische Landeskunde. Zweiter Teil. Die Völker und die Städte des antiken Hispanien. Band 1. Baetica, Baden-Baden.

Tovar, A., 1976, Iberische Landeskunde. Zweiter Teil. Die Völker und die Städte des antiken Hispanien. Band 2. Lusitanien, Baden-Baden.

Tovar, A., 1989, Iberische Landeskunde. Segunda parte. Las tribus y las ciudades de la antigua Hispania. Tomo 3. Tarraconensis, Baden-Baden.

Untermann, J., Monumenta Linguarum Hispanicarum, Band I-V, Wiesbaden: Dr. Ludwig Reichert, 1975-2019.

UntermanN, J., 1965, Elementos de un atlas antroponímico de la Hispania Antigua, Madrid.

Untermann, J., 1973, "Le nom de Narbonne et la langue de ses habitants», Narbonne. Archéologie et histoire, Montpellier: 163-167.

Untermann, J., 1987, «Lusitanisch, Keltiberisch, Keltisch», Studia Palaeohispanica. Actas del IV Coloquio sobre lenguas y culturas paleohispánicas (Vitoria-Gasteiz 1985), Veleia 2-3, 57-76.

Untermann, J., 1992, «Los etnónimos de la Hispania antigua y las lenguas prerromanas de la Península Ibérica», Complutum 2-3: 19-33.

UNTERMANN, J., 2001, "La toponimia antigua como fuente de las lenguas hispano-celtas», $\mathrm{Pa}$ laeohispanica 1, 187-218.

VV.AA., Tabula Imperii Romani, Oxford: Oxford University Press, 1934, 1939, 1987.

$$
\begin{array}{r}
\text { ARÁNZAZu López FernÁNDEZ } \\
\text { Universidad del País Vasco (UPV/EHU) } \\
\text { aranzazu.lopez@ehu.eus } \\
\text { http://orcid.org/0000-0001-9502-3472 } \\
\text { DOI: https://doi.org/10.1387/veleia.21453 }
\end{array}
$$

